\title{
Management strategy of Type A Aortic Dissection in a developing center from China: 16 years experiences
}

\author{
Yuzhou Lu ${ }^{1,2,3}$, Yunxing Xue ${ }^{1,2,3}$, He Zhang ${ }^{2,3}$, Wei Xie ${ }^{1,2,3}$, Weiwei Zhao ${ }^{2,3}$, Dongjin Wang ${ }^{1,2,3}$, Qing Zhou ${ }^{2,3}$ \\ ${ }^{1}$ Nanjing Drum Tower Hospital, Clinical College of Nanjing Medical University, Nanjing, China; ${ }^{2}$ Department of Cardiothoracic Surgery, Nanjing \\ Drum Tower Hospital, The Affiliated Hospital of Nanjing University Medical School, Nanjing, China; ${ }^{3}$ Institute of Cardiothoracic Vascular Disease, \\ Nanjing University, Nanjing, China \\ Contributions: (I) Conception and design: Y Lu; Y Xue; (II) Administrative support: D Wang; Q Zhou; (III) Provision of study materials or patients: \\ D Wang; Q Zhou; (IV) Collection and assembly of data: Y Lu; Y Xue; H Zhang; W Xie; W Zhao; (V) Data analysis and interpretation: Y Lu; (VI) \\ Manuscript writing: All authors; (VII) Final approval of manuscript: All authors. \\ Correspondence to: Qing Zhou, MD, PhD. 321 Zhongshan Road, Nanjing 210000, China. Email: qingzhou_gl@163.com.
}

\begin{abstract}
Background: Type A Aortic Dissection (TAAD) remains a lethal disease of increasing incidence. However the incidence, standardized treatment and survival rates of TAAD is still a lack in China. This study aims to share the management strategy of TAAD from a developing center of this country.

Methods: All subjects identified with TAAD in Nanjing Drum Tower Hospital, China, from Jan. 2002 to Dec. 2018 were included in this study. Of 1,037 individuals, 932 (89.9\%) were underwent surgery. Based on annual case volume patients underwent surgery were stratified into three operative stages : Early, Middle and Current stage, and patient characteristics, operative trends and outcomes across the operative stages were assessed.
\end{abstract}

Results: The annual admissions of patients increased from approximately 20 during 2002-2013 (early era), 100 during 2014-2016 (middle era) to 200 during 2017-2018 (current era). The median age of patients increased from 49.0 to 53.0 among different eras $(\mathrm{P}<0.001)$. The overall in-hospital mortality was $16.5 \%$, which significantly decreased from $21.3 \%$ to $13.1 \%$ with eras $(\mathrm{P}=0.023)$. The median time from admission to surgery was remarkedly shorted from $30.4 \mathrm{~h}$ during the early era to $14.0 \mathrm{~h}$ during the current era. Compared with in the early era, the percentages of aortic arch repair were increased in middle or current eras, while total arch replacement decreased.

Conclusions: During the last 16 years, the prevalence of TAAD was increasing, and the annual number of operations increased substantially in China. Hospital survival improved over time was challenging prompt management and suitable operations.

Keywords: Type A Aortic Dissection (TAAD); management; morbidity; mortality

Submitted May 07, 2020. Accepted for publication Sep 15, 2020.

doi: $10.21037 /$ jtd-20-1866

View this article at: http://dx.doi.org/10.21037/jtd-20-1866

\section{Introduction}

Type A Aortic Dissection (TAAD) is a lethal cardiovascular disease associated with high morbidity and mortality, even with the increase of surgical and perioperative management methods $(1,2)$. Whether it is elective or emergency cases, management for TAAD remains a challenge.

Techniques in this area have evolved for the past two decades, such as diagnostic imaging, cardiac anesthesia, neuroprotective strategies, surgical strategies $(3,4)$. Many experienced aortic centers in developed countries have revealed the trend of decreasing mortality and morbidity with the time (5). Contemporary operative mortalities from high volume aortic centers was $10-19 \%$, which was significantly better than historical operative outcomes with mortalities of $25-31 \%(5,6)$. 
In China, an explosive growth of the overall volume of TAAD induced the increased surgical volume (7), but few reports had shown the changing situations about the demography, management strategy and postoperative outcomes. Therefore, we retrospectively review our experience in management for TAAD over the last sixteen years. We purpose to access the overall evolution of the management strategy and outcomes of TAAD at our single center. We present the following article in accordance with the STROBE reporting checklist (available at http:// dx. doi. org/10. 21037/jtd-20-1866).

\section{Methods}

\section{Patients}

All patients diagnosed with TAAD at Nanjing Drum Tower Hospital between January 1, 2002, and December 31, 2018, were retrospectively reviewed. The patients were diagnosed by chest enhanced computed tomography (CT). The exclusion criteria were aortic diseases other than TAAD, for example, type B aortic dissection, aortic aneurysm, and intramural hematoma. At last, 1,037 consecutive patients were enrolled. We retrospectively collected clinical data on the 1,037 TAAD patients on the basis of medical charts and laboratory test reports. Patients underwent surgery were stratified into three operative stages based on annual case volume: Early, Middle and Current stage. Then we assessed patient characteristics, operative trends and outcomes across the operative stages.

The study was conducted in accordance with the Declaration of Helsinki (as revised in 2013). This study was approved by the institutional research ethics committee of Nanjing Drum Tower Hospital (No. 202018501). The requirement to obtain informed consent from the patient was waived.

\section{Variables and definitions}

We collected a series of 45 pre-, intra- and post-operative variables for each patient. Malperfusion syndromes were defined by clinical evidence of abnormalities in organ perfusion, which included: cerebral malperfusion as indicated by neurological dysfunction; coronary malperfusion with ECG evidence of myocardial ischaemia; mesenteric malperfusion with raised lactate or an acute surgical abdomen; limb malperfusion with loss of pulses, weakness or numbness. Major morbidity included re- exploration, prolonged ventilation lasting $>48$ hours, permanent stroke, renal failure with the standard of creatinine $>353.6 \mu \mathrm{mol} / \mathrm{L}$ according to the KDIGO criteria, and deep sternal wound infection. Postoperative mortality was assessed by 30-days or in-hospital mortality.

\section{Surgical strategy}

If the patient has presented with unstable symptoms such as tamponade or organ malperfusion when arriving at the hospital, the patient would be transferred to the operating room directly; and stable patients were transported to the cardiovascular intensive care unit for thorough preoperative evaluation and preparation. All patients with acute TAAD underwent urgent or emergent repair.

Cardiopulmonary bypass (CPB) and deep hypothermic circulatory arrest (DHCA) were used for surgical management. Peripheral cannulation for CPB was femoral or axillary artery cannulation, or both. Antegrade perfusion of the coronary artery plus retrograde perfusion from the coronary sinus was used for intraoperative myocardial protection. The circulatory arrest was instituted once adequate cooling was achieved. Unilateral selective antegrade cerebral perfusion (ACP) was performed via the right axillary artery, or retrograde cerebral perfusion (RCP) was started via the superior vena cava cannula. The extent of aortic replacement was determined by each patient's anatomic and clinical characteristics, and also by the experience of the operating surgeon. Frozen elephant trunk (MicroPort Medical Co Ltd, Shanghai, China) was applied at the same time if replacing the total arch. Otherwise, partial aortic arch replacement or antegrade-implantation arch stent was used (two kinds of stents were introduced in our center previously) $(8,9)$. The proximal root underwent Bentall procedure or root reinforcement technique, then the ascending aorta was replaced.

\section{Statistical analyses}

Continuous variables were expressed as median with an interquartile range (IQR), and categorical variables were expressed as count (percentage). We utilized the MannWhitney $\mathrm{U}$ test for continuous variables and Chi-Square for categorical variables. The Kaplan-Meier survival analysis was used to estimate survival curves. Missing Data were noted in the $\mathrm{N}$ of each variable. Variables with less than $10 \%$ missing data were included for analysis with missing values addressed by the median for continuous variables. 

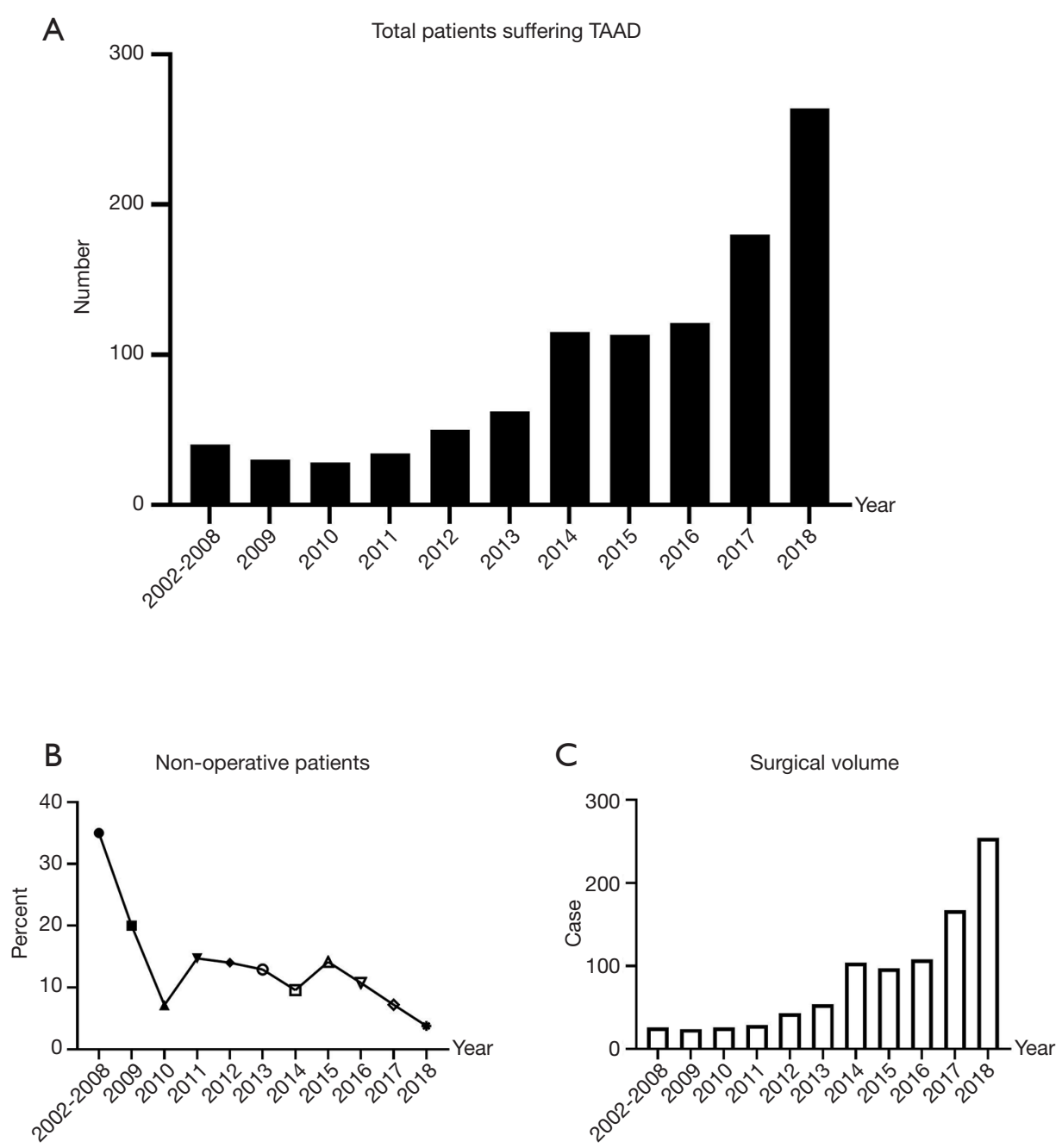

Figure 1 Total volume and surgical volume. (A) Number of all patients with Type A Aortic Dissection each year; (B) proportion of patients who died before surgery; (C) annual surgical volume of Type A Aortic Dissection.

SPSS Version 25.0 (IBM/SPSS, Chicago, IL) was used for all analyses, and $\mathrm{P}$ values less than 0.05 were considered statistically significant.

\section{Results}

A total of 1,037 patients with TAAD were reviewed at our center. Among them, 105 patients (10.1\%) had not received surgical therapy because of death before operation or refusal to surgery. The annual number of hospital patients increased rapidly from 3 in 2002 to 264 in 2018 (Figure 1A), while the rate of these non-operative patients decreased significantly from $35 \%$ to $3.79 \%$ (Figure $1 B$ ).

The annual surgical volume was less than 50 between 2002 to 2013, which increased to around 100 between 2014 to 2016, and to 200 or higher between 2017 to 2018 (Figure 1C). To show the characteristics of management strategy in different periods, we divided patients into three cohorts based on the primary surgery year: early stage $(\mathrm{n}=202$, surgery year between 2002-2013), middle stage ( $n=309$, surgery year between 2014-2016), and current stage $(\mathrm{n}=421$, surgery year between 2017-2018). 
Table 1 Demographics of patients with Type A Aortic Dissection

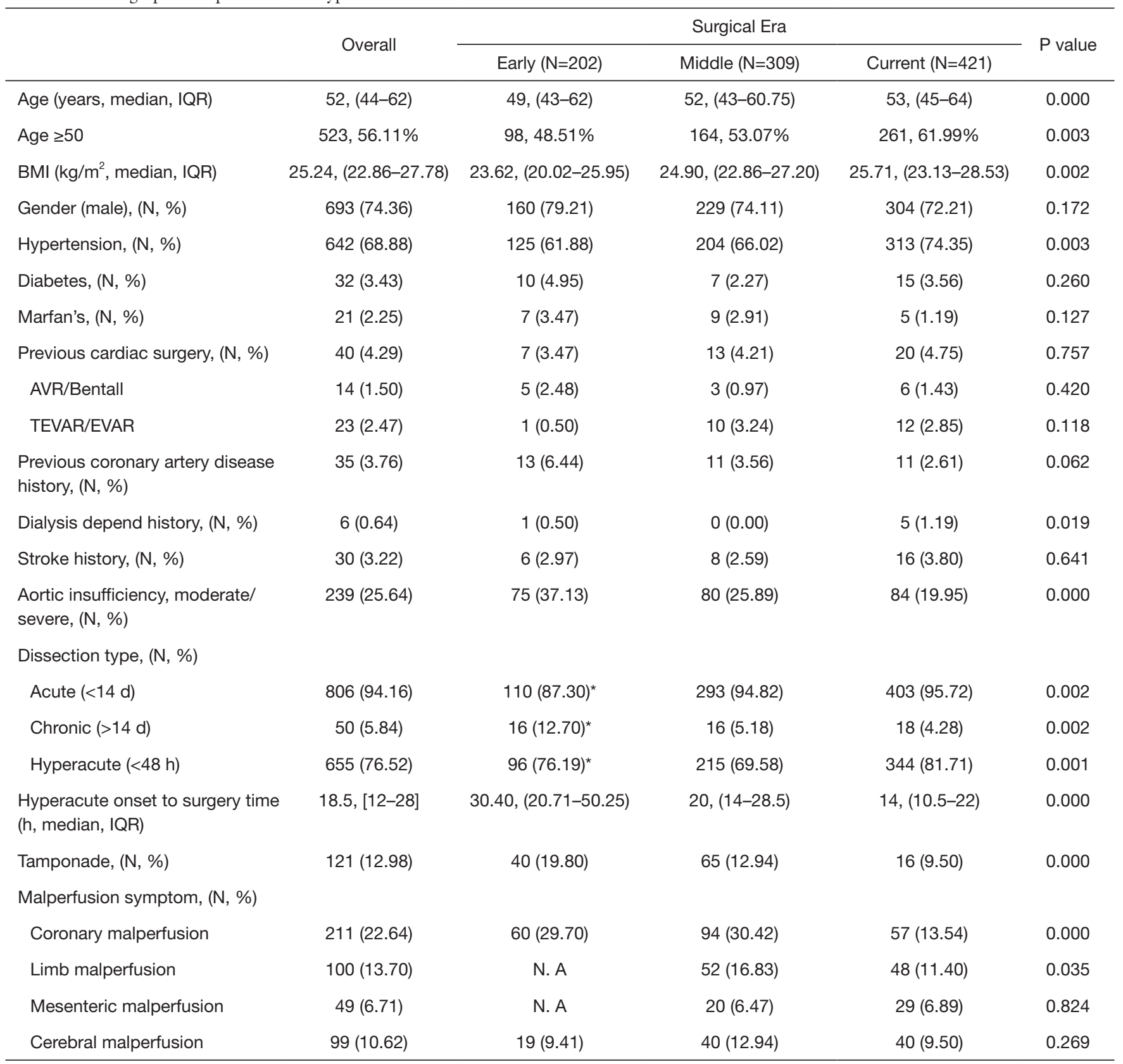

IQR, interquartile range; BMI, body mass index; AVR, aortic valve replacement; TEVAR, thoracic endovascular aortic repair; EVAR, endovascular aneurysm repair.

\section{Patients underwent surgical therapy}

The median age for all patients was 52 years old (range from 19 to 85 years old, Table 1). The proportion of patients older than 50 years has increased over time $(48.5 \% \mathrm{vs}$. $53.1 \%$ vs. $62.0 \%, \mathrm{P}=0.003)$, and the median age was getting older (49 vs. 52 vs. $53, \mathrm{P}=0.000$ ). $74.36 \%$ of the patients were male. Median BMI for all patients was $25.2 \mathrm{~kg} / \mathrm{m}^{2}$, and a tendency towards higher BMI was seen in the three groups (23.6 vs. 24.9 vs. $25.7 \mathrm{~kg} / \mathrm{m}^{2}, \mathrm{P}=0.002$ ). The most common comorbidity was hypertension presenting in $68.88 \%$ of patients, which increased over time $(61.9 \%$ vs. $66.0 \%$ vs. $74.4 \%, \mathrm{P}=0.003)$. 
Table 2 Operative characteristics and strategies

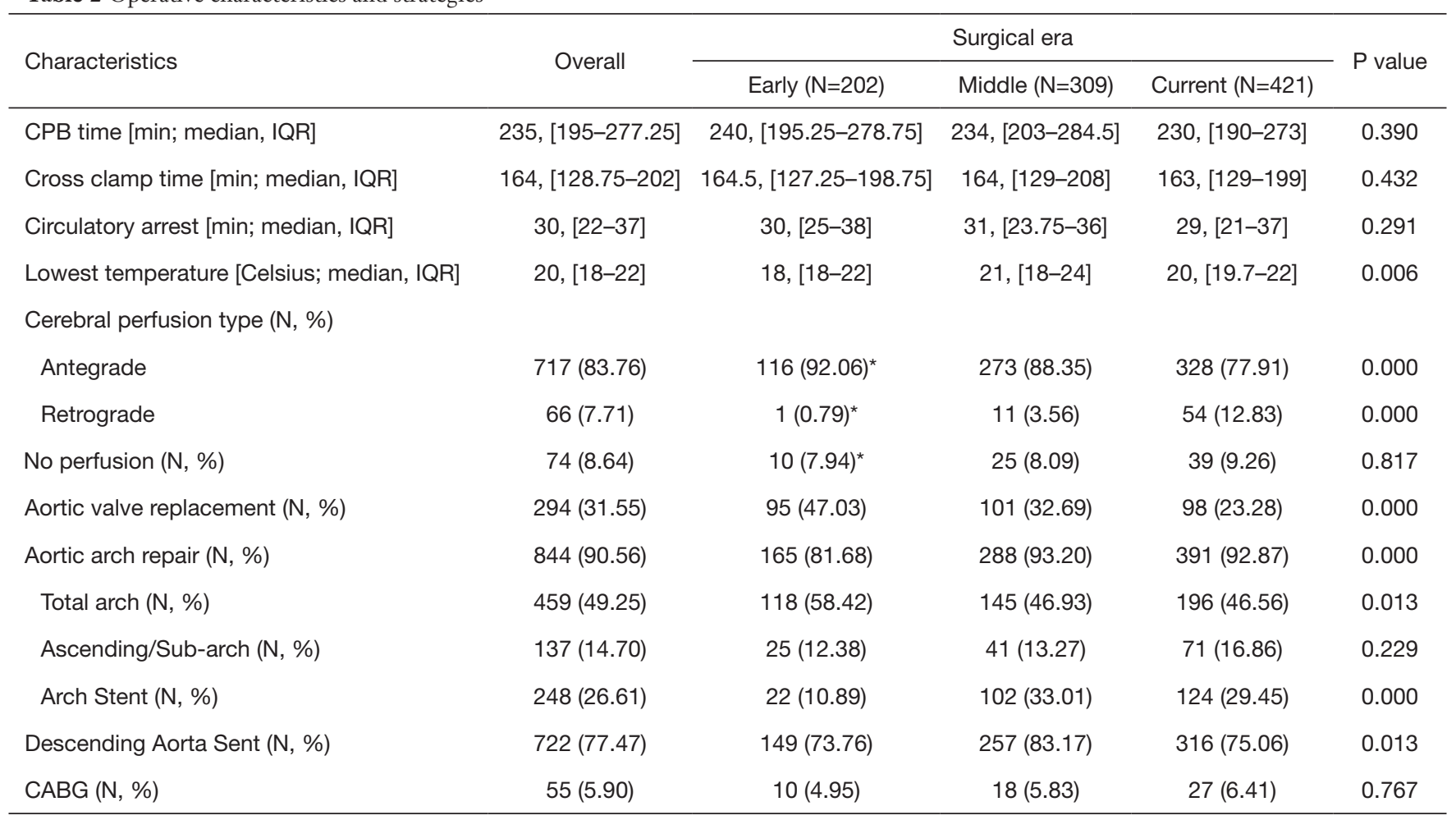

*, there is no data of Cerebral perfusion type from 2002 to $2010(\mathrm{~N}=76)$. CPB, cardiopulmonary bypass; CABG, Coronary artery bypass surgery.

Most of the patients were suffering from acute aortic dissection ( $<14$ days), and rates of the patient with chronic dissection reduced during the three eras $(12.7 \%$ vs. $5.18 \%$ vs. $4.28 \%, \mathrm{P}=0.002) .76 .5 \%$ of the patients were in the hyperacute phase ( $\leq 48$ hours from onset of symptoms/ dissection). Median timeframe from symptom onset to surgical treatment in the hyperacute phase significantly decreased (30.4 vs. 20.0 vs. 14.0 hours, $\mathrm{P}=0.000$ ). There were significantly lower rates of moderate to severe aortic insufficiency (AI) over time ( $37.1 \%$ vs. $25.9 \%$ vs. $20.0 \%$, $\mathrm{P}=0.000)$. Rates of tamponade decreased as well $(19.8 \%$ vs. $12.9 \%$ vs. $9.90 \%, \mathrm{P}=0.000)$. There were decreased rates of coronary malperfusion in the current era $(29.7 \%$ vs. $30.4 \%$ vs. $13.5 \%, \mathrm{P}=0.000)$. Rates of limb malperfusion were not available for the early era and decreased between the middle and current eras ( $16.8 \%$ vs. $11.4 \%, \mathrm{P}=0.035)$.

\section{Management strategy and outcomes}

Patients underwent increasingly different surgical management during the three eras as indicated by some significant differences in intra-operative variables (Table 2). The rates of aortic arch repair $(81.7 \%$ vs. $93.2 \%$ vs. $92.9 \%$, $\mathrm{P}=0.000)$ had increased along with arch stent implantation (10.9\% vs. $33.0 \%$ vs. $29.5 \%, \mathrm{P}=0.000)$. But the rates of total arch replacement decreased obviously for the latter two eras (58.4\% vs. $46.9 \%$ vs. $46.6 \%, \mathrm{P}=0.013)$, and rates of aortic valve replacement trended towards a significant decrease over time $(58.4 \%$ vs. $46.9 \%$ vs. $46.6 \%, \mathrm{P}=0.013)$. There were more patients with sent implanted into the descending aorta from the Middle than the Early and Current (73.8\% vs. $83.2 \%$ vs. $75.1 \%, \mathrm{P}=0.013)$. There was a trend towards the current era having higher rates of RCP use at $12.8 \%$ compared to $3.56 \%$ in the middle era and $0.35 \%$ in the early era $(\mathrm{P}=0.000)$. The lowest temperature raised for the latter two eras (18 vs. 21 vs. 20 degrees Celsius, $\mathrm{P}=0.006$ ). While CPB times did not statistically decrease over time, the current era had the shortest CPB time (240 vs. 234 vs. 230 min, $\mathrm{P}=0.390$ ).

The overall 30 -day mortality was $16.5 \%$ and decreased significantly for the three eras $(21.3 \%$ vs. $18.1 \%$ vs. $13.1 \%, \mathrm{P}=0.023$, Figure 2). The length of ICU decreased 
from a median of 8 days in the early era to 6 days in the middle and finally 4 days in the current era $(\mathrm{P}=0.000$, Table 3). Prolonged ventilation trended towards a decrease from $50.0 \%$ to $37.5 \%$ and $33.3 \%(\mathrm{P}=0.000)$. The rate of permanent stroke had no change over time, although it was the lowest for the Current $5.45 \%$ vs. $3.88 \%$ vs. $2.61 \%$, $\mathrm{P}=0.203)$; the same was true for the rates of re-exploration (8.42\% vs. $6.80 \%$ vs. $6.65 \%, \mathrm{P}=0.703)$. While the rate of renal failure was not available for the early era, rates of renal failure did not statistically increase for the latter two eras (12.0\% vs. $16.2 \%, \mathrm{P}=0.112$ ). However, the rate of CRRT was significantly higher in the Current than the other earlier two eras $(6.93 \%$ vs. $6.15 \%$ vs. $16.2 \%, \mathrm{P}=0.000)$, the same as the rates of deep sternal wound infection $(1.98 \% \mathrm{vs}$. $1.29 \%$ vs. $4.28 \%, \mathrm{P}=0.040$ ).

\section{Discussion}

TAAD involves the ascending aorta and is a cardiovascular

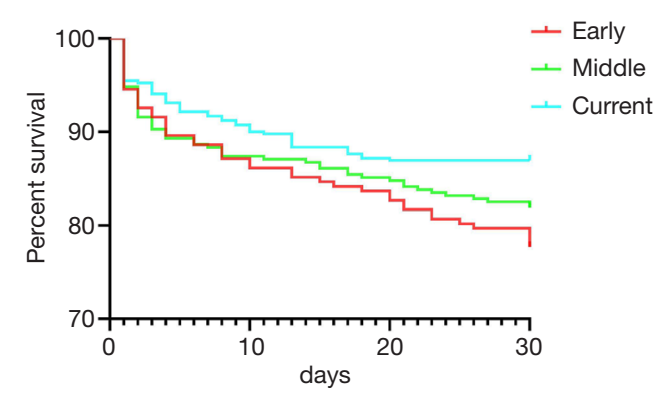

Figure 2 Thirty-day survival curve. emergency that requires urgent or emergent surgery. Population-based studies suggest that the incidence of acute aortic dissection is about 3.5 cases per 100,000 per year, which is still increasing over time $(10,11)$. The regional population is about 10 million, and it radiates to about 50 million in neighboring provinces and cities. In our region, there are about four aortic centers, which number of diagnosis and treatment for TAADs is increasing every year. At our center, the number of cases has increased from less than 20 per year in the previous period to more than 200 per year at the present stage, surgical mortality decreased from $21 \%$ to $13 \%$, and there are some significant changes contributed to the decreasing mortality over time: timeliness of diagnosis and treatment had been increased, while the status of preoperative malperfusion syndrome had decreased; some measures for cerebral protection also had some changes; more patients were treated by simplified surgical approach, as the proportion of total arch repair and aortic valve replacement decreased; postoperative complications were more aggressively intervened and rapid rehabilitation protocols had been standardized.

Recent studies suggested that surgical outcomes of TAAD may be improved when operations are performed at high-volume aortic surgery centers $(12,13)$. Bashir et al. reported that in the United Kingdom patients with TAAD who are operated on by higher-volume surgeons experience lower levels of in-hospital mortality(Mean annual volume $\geq 4$ vs. Mean annual volume $\leq 4,12.6 \%$ vs. $19.6 \%, \mathrm{P}=0.015$ ), and Chikwe et al. reported similar results in the United States $(13,14)$. Andersen et al. indicated that annual TAAD operation number of individual surgeon was one of the

Table 3 Morbidity and 30-day mortality

\begin{tabular}{|c|c|c|c|c|c|}
\hline Characteristics & Overall & \multicolumn{3}{|c|}{ Surgical era } & $P$ value \\
\hline Permanent stroke (N, \%) & $34(3.65)$ & $11(5.45)$ & $12(3.88)$ & $11(2.61)$ & 0.203 \\
\hline Renal failure (N, \%) & $105(14.38)$ & N. A & 37 (11.97) & $68(16.15)$ & 0.112 \\
\hline CRRT (N, \%) & $101(10.84)$ & $14(6.93)$ & $19(6.15)$ & $68(16.15)$ & 0.000 \\
\hline Re-exploration (N, \%) & $66(7.08)$ & $17(8.42)$ & $21(6.80)$ & $28(6.65)$ & 0.703 \\
\hline Prolonged ventilation (N, \%) & $357(38.30)$ & $101(50.00)$ & $116(37.54)$ & $140(33.25)$ & 0.000 \\
\hline ICU [day, median, IQR] & $5,[3-8]$ & $8,[6-12]$ & $6,[4-10]$ & $4,[3-6]$ & 0.000 \\
\hline 30-day mortality (N, \%) & $154(16.52)$ & $43(21.29)$ & $56(18.12)$ & 55 (13.06) & 0.023 \\
\hline
\end{tabular}

CRRT, continuous renal replacement therapy; ICU, intensive care unit. 
strongest predictors of patient survival (15). This resembles what our center's trend reveals. Since the volume in our center reached about 100 in 2014, surgeons and the surgical team have accumulated lots of experience with the declining mortality rate.

As mortality increases by $1-2 \%$ per hour after the acute presentation of TAAD, establishing a timely diagnosis and surgical treatment is paramount. Since a robust referral system and emergency green path were implemented in 2013, and the improved diagnostic capabilities in local hospitals with round-the-clock availability of CT scanning has enabled quicker and more accurate diagnosis and earlier referral to our center, it took the patients who were in hyperacute phase less time to get admission and undergo surgery. Therefore, the rate of patients who died before surgery decreased significantly. Grau et al. reported that as the timeframe between initial ED arrival and initiation of surgical treatment was significantly reduced, prolonged ventilation time, postoperative hospital stay and mortality are also greatly reduced (16). It is similar to this report from our center. A significant number of studies have analyzed outcomes for TAAD, and it is generally believed that the results of surgery are largely related to the preoperative status which is often the primary cause of postsurgical death (17). Patients with previous cardiac surgery, shock with tamponade, preoperative evidence of stroke, and coronary, visceral, or peripheral malperfusion tend to have a worse outcome $(3,18)$. Throughout the period examined, the rates of tamponade, coronary and limb malperfusion decreased significantly, which might be associated with the reduction of onset-to-admission time.

Cerebral protection is vital during surgery for TAADs. The first method of cerebral protection successfully used in aortic arch surgery was DHCA but it has temporal limits (19). In our center, the lowest intraoperative temperature increased from 18 to 20 degrees Celsius, remained in the temperature range of deep hypothermia. Implementation of cerebral perfusion is necessary for the performance of arch procedures lasting $>30$ minutes, but the best cerebral perfusion strategy is still controversial $(20,21)$. ACP provides more time for arch surgery but has more risk of cannulation-origin embolism; RCP was valid as a method of clearing particulate emboli, however, it increased the risk of transient neurologic deficit (20,22-24). $\mathrm{Hu}$ et al. reported that ACP and RCP provide similar cerebral protective utility when combined with DHCA in a meta-analysis of 5,060 patients (19). Safi et al. demonstrated that RCP is more protective in older patients, especially patients more than 70 years of age, than in younger patients (25). In our research, there was a trend towards a higher rate of RCP adopted during DHCA as the increasing rate of older patients throughout the study period.

Advances in technologies for cerebral protection prompted efforts to perform more extensive operations in the aortic arch safely; however, the extent of distal repair in TAAD remains controversial $(21,23)$. While many surgeons adopt a conservative approach with the main goal of achieving an excellent early survival, some surgeons have advocated increasing the scope of distal repair to cope with more complex dissections for over a decade. Cabasa et al. reported that the addition of distal repair will likely have long term benefit without significant added short-term risk in aortic centers (21). In our center, $90.55 \%$ of the patients underwent aortic arch repair, including $49.25 \%$ of total arch repair, $14.70 \%$ of sub-arch repair and $26.61 \%$ of arch stent. The overall rates of these procedures are significantly higher than IRAD reported rates of arch replacement (35.4\%) (17). Many studies supported that although the differences were not statistically significant, total arch replacement was associated with a trend towards lower early and late survival $(26,27)$. To reduce the complexity of the aortic arch surgery, sub-arch replacement and aortic arch stents are increasingly applicated in our center, whilst more cases received arch repair.

Our Intensive Care Team has made an effort to develop the specific practice standards and procedure of care in the process of accumulation of experience. One of the most important advances was the application of early extubation strategy during postoperative management. And the second major area of improvement was treating renal failure more aggressively. These rapid rehabilitation protocols made the ICU-stay time decreasing significantly over time.

\section{Limitations}

As a single-centered retrospective analysis, this analysis had inherent limitations and biases, including the relatively missing data on CTA and prior treatment records. Moreover, most of the patients in this study underwent surgery within a very short time after admission, and previous comorbidity data and echocardiographic data were incomplete. And there was no detailed information on some patients who died before surgery. 


\section{Conclusions}

At our center, we have identified changes in several areas in the treatment of these patients with TAAD during the 16-year period, in terms of preoperative status, cerebral perfusion, aortic arch surgery, and postoperative management. Although these changes have been a continuum, there are significant differences among the 3 study periods from 2002 to 2013, 2014 to 2016 and 2017 to 2018 in our conduct of this surgery. Due to earlier diagnosis, the number of patients undergoing surgery has greatly increased. And in the aging population with increasing comorbidities in our region, this study population has demonstrated a trend towards older age. Through various technical changes with theoretical benefits and the accumulation of experience of surgical treatment team, operative mortality of TAAD has fallen over time in our center.

\section{Acknowledgments}

Funding: None.

\section{Footnote}

Reporting Checklist: The authors have completed the STROBE reporting checklist. Available at http://dx.doi. org/10.21037/jtd-20-1866

Data Sharing Statement: Available at http://dx. doi. org/10. 21037/jtd-20-1866

Peer Review File: Available at http://dx. doi. org/10. 21037/ jtd-20-1866

Conflicts of Interest: All authors have completed the ICMJE uniform disclosure form (available at http://dx. doi. org/10. 21037/jtd-20-1866). The authors have no conflicts of interest to declare.

Ethical Statement: The authors are accountable for all aspects of the work in ensuring that questions related to the accuracy or integrity of any part of the work are appropriately investigated and resolved. The study was conducted in accordance with the Declaration of Helsinki (as revised in 2013). This study was approved by the institutional research ethics committee of Nanjing Drum Tower Hospital (No. 202018501). The requirement to obtain informed consent from the patient was waived.

Open Access Statement: This is an Open Access article distributed in accordance with the Creative Commons Attribution-NonCommercial-NoDerivs 4.0 International License (CC BY-NC-ND 4.0), which permits the noncommercial replication and distribution of the article with the strict proviso that no changes or edits are made and the original work is properly cited (including links to both the formal publication through the relevant DOI and the license). See: https://creativecommons.org/licenses/by-nc-nd/4.0/.

\section{References}

1. Golledge J, Eagle KA. Acute aortic dissection. Lancet 2008;372:55-66.

2. Siegal EM. Acute aortic dissection. J Hosp Med 2006;1:94-105.

3. Narayan P, Rogers CA, Davies I, et al. Type A aortic dissection: has surgical outcome improved with time? J Thorac Cardiovasc Surg 2008;136:1172-7.

4. Nienaber CA, Clough RE. Management of acute aortic dissection. Lancet 2015;385:800-11.

5. Hawkins RB, Mehaffey JH, Downs EA, et al. Regional Practice Patterns and Outcomes of Surgery for Acute Type A Aortic Dissection. Ann Thorac Surg 2017;104:1275-81.

6. Pape LA, Awais M, Woznicki EM, et al. Presentation, Diagnosis, and Outcomes of Acute Aortic Dissection: 17Year Trends From the International Registry of Acute Aortic Dissection. J Am Coll Cardiol 2015;66:350-8.

7. Wu J, Xie E, Qiu J, et al. Subacute/chronic type A aortic dissection: a retrospective cohort study. Eur J Cardiothorac Surg 2020;57:388-96.

8. Pan J, Li QG, Zhou Q, et al. Repair of acute type A aortic dissections using open replacement with triple-branched stent grafts. Ann Thorac Surg 2013;96:559-62.

9. Zhou Q, Xue Y, Cao H, et al. Novel arch fenestrated stent graft for acute Stanford Type A aortic dissection with open antegrade implantation. Interact Cardiovasc Thorac Surg 2018;26:369-75.

10. Clouse WD, Hallett JW, Jr., Schaff HV, et al. Acute aortic dissection: population-based incidence compared with degenerative aortic aneurysm rupture. Mayo Clin Proc 2004;79:176-80.

11. Olsson C, Thelin S, Stahle E, et al. Thoracic aortic aneurysm and dissection: increasing prevalence and improved outcomes reported in a nationwide populationbased study of more than 14,000 cases from 1987 to 2002 . 
Circulation 2006;114:2611-8.

12. Knipp BS, Deeb GM, Prager RL, et al. A contemporary analysis of outcomes for operative repair of type A aortic dissection in the United States. Surgery 2007;142:524-8; discussion 528.e1.

13. Chikwe J, Cavallaro P, Itagaki S, et al. National outcomes in acute aortic dissection: influence of surgeon and institutional volume on operative mortality. Ann Thorac Surg 2013;95:1563-9.

14. Bashir M, Harky A, Fok M, et al. Acute type A aortic dissection in the United Kingdom: Surgeon volume-outcome relation. J Thorac Cardiovasc Surg 2017;154:398-406.e1.

15. Andersen ND, Ganapathi AM, Hanna JM, et al. Outcomes of acute type a dissection repair before and after implementation of a multidisciplinary thoracic aortic surgery program. J Am Coll Cardiol 2014;63:1796-803.

16. Grau JB, Kuschner CE, Ferrari G, et al. Effects of a protocol-based management of type A aortic dissections. J Surg Res 2015;197:265-9.

17. Trimarchi S, Nienaber CA, Rampoldi V, et al. Contemporary results of surgery in acute type A aortic dissection: The International Registry of Acute Aortic Dissection experience. J Thorac Cardiovasc Surg 2005;129:112-22.

18. Evangelista A, Isselbacher EM, Bossone E, et al. Insights From the International Registry of Acute Aortic Dissection: A 20-Year Experience of Collaborative Clinical Research. Circulation 2018;137:1846-60.

19. Hu Z, Wang Z, Ren Z, et al. Similar cerebral protective effectiveness of antegrade and retrograde cerebral perfusion combined with deep hypothermia circulatory

Cite this article as: $\mathrm{Lu} \mathrm{Y,} \mathrm{Xue} \mathrm{Y,} \mathrm{Zhang} \mathrm{H,} \mathrm{Xie} \mathrm{W,} \mathrm{Zhao}$ W, Wang D, Zhou Q. Management strategy of Type A Aortic Dissection in a developing center from China: 16 years experiences. J Thorac Dis 2020;12(11):6780-6788. doi: $10.21037 /$ jtd-20-1866 arrest in aortic arch surgery: a meta-analysis and systematic review of 5060 patients. J Thorac Cardiovasc Surg 2014;148:544-60.

20. Krüger T, Weigang E, Hoffmann I, et al. Cerebral protection during surgery for acute aortic dissection type A: results of the German Registry for Acute Aortic Dissection Type A (GERAADA). Circulation 2011;124:434-43.

21. Cabasa A, Pochettino A. Surgical management and outcomes of type A dissection-the Mayo Clinic experience. Ann Cardiothorac Surg 2016;5:296-309.

22. Okita Y, Minatoya K, Tagusari O, et al. Prospective comparative study of brain protection in total aortic arch replacement: deep hypothermic circulatory arrest with retrograde cerebral perfusion or selective antegrade cerebral perfusion. Ann Thorac Surg 2001;72:72-9.

23. Chiu P, Miller DC. Evolution of surgical therapy for Stanford acute type A aortic dissection. Ann Cardiothorac Surg 2016;5:275-95.

24. Girardi LN, Shavladze N, Sedrakyan A, et al. Safety and efficacy of retrograde cerebral perfusion as an adjunct for cerebral protection during surgery on the aortic arch. J Thorac Cardiovasc Surg 2014;148:2927-33.

25. Safi HJ, Letsou GV, Iliopoulos DC, et al. Impact of retrograde cerebral perfusion on ascending aortic and arch aneurysm repair. Ann Thorac Surg 1997;63:1601-7.

26. Sabik JF, Lytle BW, Blackstone EH, et al. Long-term effectiveness of operations for ascending aortic dissections. J Thorac Cardiovasc Surg 2000;119:946-62.

27. Trivedi D, Navid F, Balzer JR, et al. Aggressive Aortic Arch and Carotid Replacement Strategy for Type A Aortic Dissection Improves Neurologic Outcomes. Ann Thorac Surg 2016;101:896-903; discussion 903-5. 